\title{
Tantangan Etika dan Hukum Penggunaan Rekam Medis Elektronik dalam Era Personalized Medicine
}

\author{
Rani Tiyas Budiyanti ${ }^{1}$, Penggalih Mahardika Herlambang ${ }^{2}$, Nurhasmadiar Nandini ${ }^{3}$ \\ Administrasi dan Kebijakan Kesehatan, Fakultas Kesehatan Masyarakat, Universitas Diponegoro, \\ Semarang ${ }^{1,3}$ \\ Prodi Rekam Medis, Fakultas Kesehatan, Universitas Dian Nuswantoro, Semarang 2 \\ ranitiyasbudiyanti@gmail.com ${ }^{1}$, pmherlambang@gmail.com², nurhasmadiar.nandini@live.undip.ac.id ${ }^{3}$
}

Submitted 19 Desember 2018 Revised 12 Januari 2019 Accepted 24 Januari 2019

\section{ABSTRAK}

Latar Belakang: Personalized medicine merupakan salah satu pendekatan pengobatan kesehatan yang berkembang dalam sepuluh tahun terakhir. Pengobatan ini bersifat spesifik karena mempertimbangkan genomik pasien dan memerlukan database atau rekam medis yang lengkap meliputi data klinis dan genomik. Meskipun demikian, terdapat isu dan tantangan etika dan hukum dalam implementasi rekam medis elektronik dalam personalized medicine.

Tujuan: Penelitian ini bertujuan untuk mengetahui tantangan etika dan hukum dalam penggunaan rekam medis elektronik dalam personalized medicine berdasarkan studi literatur yang telah ada.

Metode: Metode yang digunakan dalam penelitian ini adalah literatur review dengan sumber yang berasal dari jurnal, buku, dan artikel mengenai rekam medis elektronik, personalized medicine, serta aspek hukum dan etika yang terkait baik dalam negeri maupun luar negeri.

Hasil: Tantangan etika dan hukum yang dapat terjadi dalam penggunaan rekam medis elektronik di era personalized medicine diantaranya adalah keamanan dan kepemilikan data, tanggung jawab hukum, diskriminasi genomic, dan perubahan hubungan dokter dan pasien.

Kesimpulan: Indonesia belum memiliki regulasi spesifik mengenai keamanan data, kepemilikan data, dan sharing data di bidang kesehatan. Regulasi lebih lanjut mengenai penggunaan rekam medis elektronik di era personalized medicine diperlukan agar dalam implementasinya tidak bertentangan dengan etika dan hukum yang berlaku di Indonesia.

Kata Kunci: personalized medicine; rekam medis elektronik; etika;

\section{ABSTRACT}

Background: Personalized medicine is one of the health treatment approaches that has developed in the last ten years. This treatment is specific because it considers the genomics of patients and requires a complete database or medical record covering clinical and genomic data. Nevertheless, there are ethical and legal challenges in the implementation of electronic medical records in personalized medicine.

Objective: This study aimed to determine the ethical and legal challenges in the use of electronic medical records in personalized medicine based on previous literature.

Methods: The method used in this study was literature review with sources from journals, books, and articles on electronic medical records, personalized medicine, as well as legal and ethical aspects related both domestically and abroad.

Results: Ethical and legal challenges that can occurred in the use of electronic medical records in the personalized medicine era include security and ownership of data, legal responsibility, genomic discrimination, and changes in the relationship between doctors and patients.

Conclusion: Indonesia does not yet have specific regulations regarding data security, data ownership, and data sharing in the health sector. Further regulations regarding the use of electronic medical records in the personalized era are needed so that their implementation does not conflict with the ethics and laws that apply in Indonesia

Keywords: personalized medicine; electronic medical record; ethics; law. 


\section{PENDAHULUAN}

Perkembangan teknologi mencapai ranah kesehatan, terlebih di era 4.0. Personalized medicine merupakan salah satu pendekatan pengobatan yang telah berkembang pada sepuluh tahun terakhir (Davis and Khoury, 2005). Pengobatan ini tidak menggunakan pendekatan pengobatan berdasarkan populasi tetapi menggunakan pendekatan personal yang mempertimbangkan genomik dan keadaan atau kondisi individu (Vazquez, 2004). Konsep personal medicine atau precision medicine telah dibicarakan sejak Human Genome Project pada tahun 1990 (Bennet, 2003). Konsep ini berfokus pada tiga hal yaitu patient centered, information intensive, dan resource dependent (Rogowski etal., 2014)

Dengan pendekatan personalized medicine, pasien dapat memperoleh pengobatan yang spesifik sesuai dengan kondisi yang dialaminya dengan tingkat keberhasilan yang lebih tinggi dibandingkan population based medicine. (Brothers and Rothstein, 2015). Personalized medicine dapat menurunkan biaya pelayanan kesehatan dikarenakan mempermudah penentuan diagnosis dan membantu penentuan terapi lebih akurat, meskipun dalam implementasinya memerlukan dukungan teknologi seperti penggunaan rekam medis elektronik (Shabo, 2005).

Hal ini dikarenakan personalized medicine memerlukan data pasien secara rinci sehingga penentuan keputusan klinis dapat disesuaikan dengan kondisi genetik pasien. Data pasien dapat diperoleh melalui rekam medis pasien. Dengan rekam medis elektronik, data lebih mudah tersimpan dan dapat digunakan untuk mengambil keputusan klinis (Shabo, 2005).

Meskipun demikian, penggunaan rekam medis elektronik dalam personalized medicine memiliki tantangan etika dan hukum seperti privasi data, keamanan data, protokol etik penggunaan dan kepemilikan data, diskrimnasi genomik, dan sebagainya. Penelitian ini bertujuan untuk mengetahui tantangan etika dan hukum penggunaan rekam medis elektronik di era personalized medicine.

\section{METODE}

Penelitian ini menggunakan metode literatur review dengan tahapan penentuan topik, penentuan ruang lingkup topik, pemilihan sumber pustaka yang berasal dari buku, jurnal, maupun artikel nasional maupun internasional mengenai rekam medis elektronik, personalized medicine, serta aspek etika dan hukum yang berkaitan dengan rekam medis dan personalized medicine. Selanjutnya dilakukan literatur review sesuai dengan topik atau permasalahan mengenai tantangan etika dan hukum dalam penerapan rekam medis elektronik di era personalized medicine.

\section{HASIL DAN PEMBAHASAN}

\section{Penggunaan Rekam Medis Elektronik dalam Personalized Medicine}

Rekam medis elektronik menjembatani pemberian informasi antara dokter, pasien, dan rumah sakit. Beberapa dekade terakhir, rekam medis elektronik mengalami transisi dari yang semula paper-based menjadi electronic-based (Saif etal., 2011).

Inovasi ini sejalan dengan pengembangan teknologi kedokteran termasuk di dalamnya adalah personalized medicine. Pada prinsipnya, personalized medicine adalah penetapan diagnosis, prognosis, dan strategi pengobatan berdasarkan kebutuhan masing-masing pasien (Chouchane et al., 2011). Personalized medicine yang juga disebut dengan precision atau systems medicine memerlukan data lengkap untuk membantu penentuan diagnosis dan terapi. Seperti contohnya dalam kanker, terapi berdasarkan gen pasien dapat dilakukan (Chouchane et al., 2011).

Dengan alasan tersebut, rekam medis elektronik yang modern diperlukan sehingga lebih efektif dan efisien dalam penentuan personalized medicine. Ontario Personalized Medicine Network Subcomitte Report (OPMN) menampilkan sebuah analisis dari konsesus yang dihadiri oleh tiga wilayah yaitu Amerika, Inggris, dan sebagian negara di Eropa. Dalam 
konsensus tersebut didapatkan data bahwa terdapat ledakan dari data molecular yang berpotensi meningkatkan kesehatan individu (Ontario Personalized Medicine Network Subcomitte Report (OPMN), 2013).

Disebutkan pula bahwa large database diperlukan dalam meningkatkan kesehatan. Data tersebut dapat diperoleh dari rekam medis elektronik (RME) yang memuat datadata yang diperlukan yang terdiri dari riwayat medis pasien dan keluarga, hasil laboratorium hemotologi dan kimia klinik, complete genome sequence, metabolomics, proteomics, status imun tubuh, medical imaging, dan paparan lingkungan (Ontario Personalized Medicine Network Subcomitte Report (OPMN), 2013).

Integrasi data genomik dengan RME merupakan tantangan tersendiri dalam era personalized medicine. Health Level-7 (HL-7) sebagai standar format data RME yang diakui internasional telah mengembangkan model integrasi tersebut sejak tahun 2013 pada versi 2. (Health Level Seven International, 2013). Pada model tersebut memungkinkan hasil pemeriksaan genetik di laboratorium klinis pasien dapat disimpan dalam sistem RME dan data warehouse institusi penelitian untuk keperluan pendukung keputusan klinis (clinical decision support) (Health Level Seven International, 2013).

Kemudian konsorsium HL-7 mengembangkan versi baru yaitu Fast Healthcare Interoperability Resource (FHIR) yang didalamnya terdapat modul clinico-genomic (Tran, Zimmerman and Fielding, 2017). Modul ini terintegrasi dengan data peta genomik Global Alliance for Genomic and Health (GA4GH) yang memungkinkan berbagi data genomik lewat Substitutable Medical Aplication and Reusable Technology (SMART) di dalam FHIR (Alterovitz et al., 2015). GA4GH sendiri merupakan organisasi nirlaba internasional penetapan kebijakan dan penetapan standar teknis, yang berupaya untuk memungkinkan pembagian data genom yang bertanggung jawab (Global Alliance for Genomics and Health, 2017).

\section{Aspek Etika dan Hukum}

Selain tantangan integrasi data klinis dan genomik, tantangan dalam implementasi penggunaan rekam medis elektronik dalam era personalized medicine adalah tantangan etika dan hukum. Terdapat beberapa isu etika dan hukum seperti permasalahan privasi dan kepemilikan data pasien, diskriminasi genomik, pergeseran hubungan dokter dan pasien, serta permasalahan mengenai tanggung jawab hukum.

\section{Privasi dan kepemilikan data pasien}

Privasi merupakan suatu kondisi yang membatasi akses terhadap informasi seseorang salah satunya informasi mengenai kesehatan seseorang. Privasi berhubungan dengan konfidensialitas yang merupakan keadaan untuk menjaga kerahasiaan pasien dan tidak memberikan informasi ke orang lain tanpa persetujuan pemilik data. Hal ini diatur lebih lanjut dalam Peraturan Menteri Kesehatan Nomor 269 tahun 2008 tentang Rekam Medis (Kementerian Kesehatan Republik Indonesia, 2008).

Hal yang penting dalam privasi adalah keamanan data (security) sehingga tidak terjadi kebocoran data ke pihak lain. Kejadian serangan siber (cyberattack) dapat diminimalisir dengan peningkatan cybersecurity dengan evaluasi dan uji keamanan jaringan yang dilakukan secara berkala (Budiyanti, Arso and Herlambang, 2018).

Dalam beberapa konsep hukum terdapat alasan mengapa proteksi informasi keshatan seseorang sangat penting. Pertama, informasi kesehatan seseorang dapat menyebabkan munculnya stigma dan diskriminasi jika terbuka secara bebas. Kedua, kualitas layanan kesehatan akan mengalami penurunan jika pasien yang menderita suatu penyakit mengalami stigma dan diskriminasi dari lingkungan. Ketiga, pasien dengan penyakit infeksius, gangguan kejiwaan, penyalahgunaan obat, atau kondisi yang sensitive lainnya akan menolak untuk mendapatkan terapi karena takut terbuka 
privasinya. Informasi kesehatan juga penting dalam hal asuransi dan permasalahan jaminan kesehatan (Brothers and Rothstein, 2015).

Perlindungan terhadap data pribadi juga diatur dalam Pasal 2 ayat (1) Peraturan Menteri Komunikasi dan Informatika Nomor 20 tahun 2016 tentang Perlindungan Data Pribadi dalam Sistem Elektronik, yang menyebutkan bahwa perlindungan data pribadi dalam sistem elektronik mencakup perlindungan terhadap perolehan, pengumpulan, pengolahan, penganalisisan, penyimpanan, penampilan, pengumuman, pengiriman, penyebarluasan, dan pemusnahan data pribadi. (Menteri Komunikasi dan Informatika, 2016).

Dengan perkembangan rekam medis elektronik maupun electronic health record (EHR), resiko terbukanya data semakin besar, hal ini dikarenakan RME terutama yang mengkombinasikan data klinik dan genomik memiliki data kesehatan pasien yang lengkap dan terintegrasi, dan terupdate. Terlebih lagi jika RME atau EHR terintegrasi dengan asuransi. Sehingga perlu adanya regulasi untuk memberi batasan dan segmentasi data yang boleh diakses dan tidak boleh diakses diakses oleh orang lain. Di era personalized medicine dan perkembangan teknologi informasi, pasien seringkali dapat mengakses rekam medisnya dan memonitoring riwayat kesehatannya sendiri. Sehingga mereka dapat lebih bertanggung jawab terhadap kesehatannya (Brothers and Rothstein, 2015).

\section{Diskriminasi genomik}

Diskriminasi pada umumnya lebih mengarah kepada seseorang yang mendapatkan perbedaan perlakuan baik dalam hukum atau sosial. Dalam era personalized medicine, genetic seseorang dapat dengan mudah diketahui terlebih jika dilakukan data sharing. Meskipun dilakukan enkripsi data, akan tetapi diskriminasi terhadap ras atau genetik dapat terjadi dan menyebabkan perbedaan perlakuan dalam masyarakat (Brothers and Rothstein, 2015).

Hal ini juga berhubungan dengan permasalahan asuransi dimana sedikit permasalahan genetik juga akan memiliki pengaruh yang signifikan terhadap ekonomi. Seperti contohnya dalam pemeriksaan genetik seseorang, terdapat potensi orang tersebut menderita penyakit tertentu di kemudian hari. Tetapi jika pasien tersebut tidak melakukan pengobatan secara standar, maka akan terjadi peningkatan morbiditas dan mortalitas yang akan berpengaruh dalam hal jaminan kesehatan. Banyak kemudian pihak asuransi yang enggan menanggung nasabah yang memiliki kemungkinan permasalahan kesehatan yang cukup banyak, atau kemudian pihak asuransi akan meminta polis yang cukup besar (Rothstein and Joly, 2009).

Dalam hal ini diperlukan pembatasan akses, siapa sajakah yang boleh mengakses informasi kesehatan tersebut dan sejauh mana akses yang diperbolehkan (Budiyanti, Arso and Herlambang, 2018).

\section{Pergeseran hubungan dokter dan pasien}

Personalized medicine juga akan memberikan pengaruh yang cukup besar dalam hubungan dokter dan pasien. Di era pre genomik, diagnosis dan pengobatan penyakit genetik akan dilakukan oleh ahli genetika, dokter anak, dokter saraf, ahli onkologi, dan spesialis lain yang lebih spesifik. Di era personalized medicine, akan terjadi pergeseran pengobatan. Penyakit monogenik yang jarang seperti asma, hipertensi, diabetes militus akan banyak ditemukan dan ditangani oleh dokter (Stanek et al., 2012).

Hal yang kemudian menjadi permasalahan adalah apakah para tenaga $\mathrm{k}$ e s e hat a $\mathrm{n}$ e r s e but m a m u menginterpretasikan hasil sekuen genomick merencanakan strategi pencegahan dan pengobatan berdasarkan informasi genomik dan menerapkan prinsip farmakogenomik dalam peresepannya. Meskipun personalized medicine memiliki berbagai keuntungan, tetapi potensi ketidakpuasan anatara dokter dan pasien dapat berkembang, terutama jika dokter tidak mampu memberikan pencegahan dan 
pengobatan berdasarkan informasi genomik yang didapatkan (Brothers and Rothstein, 2015).

\section{Tanggung jawab hukum (liability)}

Perekembangan personalized medicine menuntut kapasitas tenaga kesehatan untuk memberikan pengobatan sesuai standar dan kelimuan terkini. Penggunaan teknologi kesehatan yang modern dan kompleks tentu saja akan berpotensi meningkatkan resiko dan eror yang dapat merugikan pasien. Tuntutan terhadap kerugian pasien dapat terjadi dan dapat berujung pada tuntutan malpraktik medik.

Dalam hal ini, standar dari teknologi kesehatan sangat diperlukan sehingga dapat dibedakan apakah kesalahan yang terjadi akibat human error ataukah device error yang berpengaruh kepada tanggung jawab hukum atau liability (Knoppers, 2001). Jikalaupun terjadi device error, pihak yang harus bertanggung jawab sebaiknya juga disepakati sehingga terdapat monitoring terhadap standarisasi dan keamanan alat atau teknologi yang digunakan.

Untuk menghindari keselahan manusia (human error), tenaga kesehatan pun sebaiknya juga mendapatkan pengetahuan dan pelatihan berkala sehingga tidak melakukan kesalahan yang dapat merugikan pasien.

\section{PENUTUP}

Rekam medis elektronik yang modern diperlukan dalam penentuan personalized medicine sehingga lebih efektif dan efisien. Terdapat tantangan etika dan hukum dalam penerapan rekam medis elektronik yaitu kepemilikan dan privasi data, diskriminasi genomik, pergeseran hubungan dokter dan pasien, serta tanggung jawab hukum (liability). Indonesia perlu mengatur lebih lanjut penggunaan rekam medis elektronik di era personalized medicine sehingga implementasinya tidak bertentangan dengan etika dan hukum yang berlaku.

\section{DAFTAR PUSTAKA}

Alterovitz, G. et al. (2015) 'SMART on FHIR Genomics: Facilitating standardized clinico-genomic apps', Journal of the American Medical Informatics Association, 22 (6), p p . 1173-1178. doi: 10.1093/jamia/ocv045.

Bennet, C. (2003) 'The human Genome Project and The Future of Medical Practice', African Journal of Biotechnology, 2(12), pp. 649-656.

Brothers, K. B. and Rothstein, M. A. (2015) 'Ethical, legal and social implications of incorporating personalized medicine into healthcare', Personalized Medicine, pp. 43-51. doi: 10.2217/pme.14.65.

Budiyanti, R. T., Arso, S. P. and Herlambang, P. M. (2018) 'Rekam Medis Elektronik Berbasis Cloud', Cermin Dunia Kedokteran Edisi 268, 45(9).

Chouchane, L. et al. (2011) 'Personalized medicine: A patient - centered paradigm', Journal of Translational Medicine. doi: 10.1186/1479-5876-9-206.

Davis, R. and Khoury, M. (2005) 'The journey of personalized medicine', Personalized Medicine, 2(1), pp. 1-4. doi: doi: 10.1517/17410541.2.1.1.

Global Alliance for Genomics and Health (2017) Overview of Global Alliance for Genomics and Health. Available at: https://www.ga4gh.org/aboutus/.

Health Level Seven International (2013) HL7 Version 2 Implementation Guide: Clinical Genomics; Fully LOINC-Qualified Genetic Variation Model (US Realm).

Kementerian Kesehatan Republik Indonesia (2008) Peraturan Menteri Kesehatan Nomor 269 tahun 2008 tentang Rekam Medis. Indonesia.

Knoppers, B. M. (2001) 'Duty to recontact: a legal harbinger?', American Journal of Medical Genetics, 103(4), p. 277. Available a $\mathrm{t}$ : http://onlinelibrary.wiley.com/doi/10.10 02/ajmg.1543/abstract.

Menteri Komunikasi dan Informatika (2016) 
Peraturan Menteri Komunikasi dan Informatika Nomor 20 tahun 2016 Tentang Perlindungan Data Pribadi, Republik Indonesia. doi: 10.1111/j.14697610.2010.02280.x.

Ontario Personalized Medicine Network Subcomitte Report (OPMN) (2013) Summary of International Strategies for Personalized Medicine. Available at: http://www.ontariogenomics.ca/wpcontent/uploads/sites/1/2015/09/OPMNREPORTS_SummaryofInternationalStra tegiesforPersonalizedMedicine.pdf (Accessed: 18 December 2018).

Rogowski, W. et al. (2014) 'Concepts of "Personalization" in Personalized Medicine: Implications for Economic Evaluation', PharmacoEconomics, 33(1), pp. 49-59. doi: 10.1007/s40273-014-02115.

Rothstein, M. A. and Joly, Y. (2009) 'Genetic in formation and insurance underwriting: contemporary issues and approaches in the global economy', in Atkinson, P. A., Glasner. Peter Egon, and Lock, M. (eds) Handbook of Genetics and Society: Mapping the New Genomic Era. New York: Routledge, pp. 127-144. A v a i $1 \mathrm{able}$ a $\mathrm{t}$ : https://yannjoly.openum.ca/publication s/genetic-information-and-insuranceunderwriting-contemporary-issuesand-approaches-in-the-globaleconomy-insurance/.

Saif, S. M. et al. (2011) 'A Network engineering Solution for Data sharing across healthcare providers and protects patients health data privacy using EHR System', Journal of Global Research in Computer Science, 2(8), pp. 67-72. A v a i 1 a ble a $\mathrm{e}$ : http://capella.summon.serialssolutions.c om/link/eJx9Uttum0AQJZdW6iWfkbys wBh8AUs0cuukTRsnbWiaqi_WsDuYT $\begin{array}{llllllllllll}\mathrm{W} & \mathrm{C} & \mathrm{X} & 7 & \mathrm{i} & 4 & 4 & & \mathrm{r} & 1 & -\end{array}$ W9c4iVqp6gNizpkzZy7gOG_S6_n88sJ NT9L0zL6rFWaBVyvJPN1U1RSeRsWh1 FqWjeFSaI_Kyg3C4dgdRoMd5XNt_j8y_B8Fn7e3f1VGFNPer1VG5c_hy ULa1sOihb_dPFKnilQa49CjWU.

Shabo, A. (2005) 'The implications of electronic health record for personalized medicine.', Biomedical papers of the Medical Faculty of the University Palack??, Olomouc, Czechoslovakia, 149(2). doi: 10.2217/17410541.2.3.251.

Stanek, E. J. et al. (2012) 'Adoption of pharmacogenomic testing by US physicians: Results of a nationwide survey', Clinical Pharmacology and Therapeutics, 91(3), pp. 450-458. doi: 10.1038/clpt.2011.306.

Tran, L. D., Zimmerman, F. J. and Fielding, J. E. (2017) 'Public health and the economy could be served by reallocating medical expenditures to social programs', SSM Population Health, 3, pp. 185-191. doi: 10.1016/j.ssmph.2017.01.004.

Vazquez, E. S. (2004) 'Personalized therapy: an interdisciplinary challenge', Personalized Medicine, 1(1), pp. 127-130. Available at: http://www.futuremedicine.com/doi/ab s/10.1517/17410541.1.1.127. 